Rainer Krull ORCID iD: 0000-0003-2821-8610

\title{
A fully online sensor-equipped, disposable multiphase microbioreactor as a screening platform for biotechnological applications
}

\author{
Susanna Lladó Maldonado ${ }^{1,2, *}$, Peter Panjan ${ }^{3, *}$, Shiwen Sun ${ }^{4, *}$, Detlev Rasch ${ }^{1,2}$, \\ Adama Sesay $^{3}$, Torsten Mayr ${ }^{4}$, Rainer Krull ${ }^{1,2}$ \\ *These authors contributed equally to this work. \\ ${ }^{1}$ Institute of Biochemical Engineering, Technische Universität Braunschweig, 38106 \\ Braunschweig, Germany \\ ${ }^{2}$ Center of Pharmaceutical Engineering (PVZ), Technische Universität Braunschweig, \\ 38106 Braunschweig, Germany \\ ${ }^{3}$ Unit of Measurement Technologies, University of Oulu, Kajaani, Finland \\ ${ }^{4}$ Institute of Analytical Chemistry and Food Chemistry, Graz University of \\ Technology, 8010 Graz, Austria \\ Corresponding author: \\ Rainer Krull \\ Institute of Biochemical Engineering, Technische Universität Braunschweig, \\ Rebenring 56, 38106 Braunschweig, Germany \\ Tel.: +49 (0)531/391-55311 \\ Email: r.krull@tu-braunschweig.de
}

\begin{abstract}
A new disposable, multiphase, microbioreactor $(M B R)$ (with a working volume of $550 \mu \mathrm{L}$ ) equipped with online sensors is presented for biotechnological screening research purposes owing to its high-throughput potential. Its design and fabrication, online sensor integration, and operation are described. During aerobic cultivation, sufficient oxygen supply is the most important factor that influences growth and product formation. The $M B R$ is a microbubble column bioreactor $(\mu B C)$, and the oxygen supply was realized by active pneumatic bubble aeration, ensuring sufficient volumetric liquid-phase mass transfer $\left(k_{L} a\right)$ and proper homogenization of the

This article has been accepted for publication and undergone full peer review but has not been through the copyediting, typesetting, pagination and proofreading process, which may lead to differences between this version and the Version of Record. Please cite this article as doi: 10.1002/bit.26831.
\end{abstract}

This article is protected by copyright. All rights reserved. 
cultivation broth. The $\mu B C$ was equipped with miniaturized sensors for the $p H$, dissolved oxygen, optical density and glucose concentration that allowed real-time online monitoring of these process variables during cultivation. The challenge addressed here was the integration of sensors in the limited available space. The $M B R$ was shown to be a suitable screening platform for the cultivation of biological systems. Batch cultivations of Saccharomyces cerevisiae were performed to observe the variation in the process variables over time and to show the robustness and operability of all the online sensors in the $M B R$.

Graphical abstract

A new disposable, multiphase, microbioreactor $(M B R)$ (with a working volume of $550 \mu \mathrm{L}$ ) equipped with online sensors is presented for biotechnological screening research purposes owing to its high-throughput potential. Its design and fabrication, online sensor integration, and operation are described. During aerobic cultivation, sufficient oxygen supply is the most important factor that influences growth and product formation.

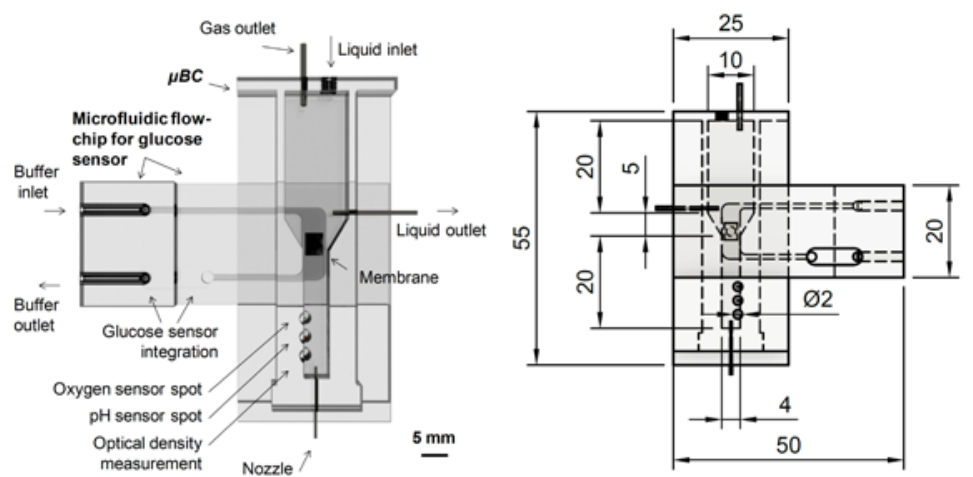

This article is protected by copyright. All rights reserved. 
Keywords: biosensor, microbioreactor, real-time online analytics, optical sensor, screening platform, sensor integration

\section{Abbreviations}

GOx glucose oxidase

HTP high-throughput processing

I light intensity

MBR microbioreactor

MTP microtiter plate

$P B \quad$ Prussian blue

PBS phosphate buffered saline

PDMS polydimethylsiloxane

PMMApoly(methyl meth-acrylate)

PtTPTBPF platinum(II) meso-tetra(4-fluorophenyl)tetrabenzoporphyrin

$R G B \quad$ Red Green Blue color model

THF tetrahydrofuran

$\mu B C$ microbubble column bioreactor

\section{Nomenclature}

CDW cell dry weight (g)

$c_{L} \quad$ concentration $(\mathrm{mmol} / \mathrm{L})$

$c_{L}{ }^{*} \quad$ saturation concentration ( $\left.\mathrm{mmol} / \mathrm{L}\right)$

$c_{X} \quad$ biomass concentration (g/L)

DO dissolved oxygen (\%)

dphi phase shift $\left(^{\circ}\right)$

$k_{L} \quad$ liquid-phase mass transfer coefficient $(\mathrm{m} / \mathrm{h})$

$k_{L} a \quad$ volumetric liquid phase mass transfer coefficient $(1 / \mathrm{h})$

$O D$ optical density (-)

This article is protected by copyright. All rights reserved. 
OTR volumetric oxygen transfer rate $(\mathrm{mmol} /(\mathrm{L} \cdot \mathrm{h}))$

OUR volumetric oxygen uptake rate $(\mathrm{mmol} /(\mathrm{L} \cdot \mathrm{h}))$

sOUR specific oxygen uptake rate $\left(\mathrm{mmol} /\left(\mathrm{g}_{\mathrm{CDw}} \cdot \mathrm{h}\right)\right)$

$\theta \quad$ mixing time (s)

\section{Introduction}

There is a high demand for cost-effective, parallel and multi-parametric automated methods for the high-throughput screening of bioprocesses (Zanzotto et al., 2004). In particular, microprocess engineered bioreactor systems, called microbioreactors (MBRs) (reaction volume of $<1000 \mu \mathrm{L}$ ), have precise control of the microenvironment and allow the collection of desired information for biotechnological process development that is relevant to the production scale (Hegab et al., 2013; Marques and Szita, 2017). Moreover, MBRs have minimal labor and cost requirements as a result of their combined features of sensor integration, automation and high-throughput processing (HTP) practicability (Perozziello et al., 2012; Zhang et al., 2007). Unfortunately, information regarding time-dependent cultivation conditions, limited process time and multi-parametric online analysis capabilities for $M B R$ s is lacking. Online analysis here is essential since the small reaction volumes of MBRs exclude sampling. For cultivations, the simultaneous detection of several parameters is mandatory for comprehensive process information.

MBRs were first introduced by the Jensen group (Szita et al., 2005; Zanzotto et al., 2004; Zhang et al., 2006) and have been developed as a screening tool for bacterial and mammalian/human cell cultivation systems, especially for biotechnological, pharmaceutical and medical process development and optimization (Krull and Peterat, 2016; Schäpper et al., 2010). The main research foci include the feasibility of online analytic integration and strain-dependent biological reaction kinetic parameter measurement. The ability to scale MBRs to the macroscale and vice versa was reproduced and validated by several reports (Demming et al., 2012; Krull and Peterat, 2016; Zanzotto et al., 2004), showing their potential to provide data and functionality similar to that of a large bioreactor system while offering the advantages of HTP, in terms of costs, space, and time. Commercial miniaturized systems in the $\mathrm{mL}$ range with integrated sensors have been also developed like the automated ambr system for cell line cultivation (Sartorius, Göttingen, Germany, working volume of 10-15 mL, equipped with $p H$ and $D O$ sensors) and the microtiter plates (MTPs) BioLector (m2plabs $\mathrm{GmbH}$, Baesweiler, Germany, $0.8-2.4 \mathrm{~mL}$ equipped with biomass, $p H, D O$, and fluorescence).

Current research is very active in this field, proof of which is in the constant publication of reviews concerning the state of the art of $M B R$ technology. Schäpper et al. (Schäpper et al., 2009) reviewed MBRs for cultivation in suspension, focusing on their fabrication materials, mass and heat transfer issues, sensing and control details, and industrial applicability. Hegab et al. (Hegab et al., 2013) gave an overview of

This article is protected by copyright. All rights reserved. 
MBR fabrication techniques as well as their operation and control. Kirk and Szita (Kirk and Szita, 2013) examined oxygen transfer in miniaturized (milliliter- ranged) bioreactors and microliter-ranged MBRs and showed comparable characteristics to bench-, pilot-, and production-scale systems. Lattermann and Büchs (Lattermann and Büchs, 2015) reviewed miniaturized bioreactors and MBR development, highlighting the mass transfer and power input characterization, optical monitoring, and automation of fed-batch screening systems. Krull et al. (Krull et al., 2016) reviewed the $M B R$ platforms used for bacterial and mammalian/human cell cultivation biotechnology and process development. Marques and Szita (Marques and Szita, 2017) recently published a review in which the main focus was the development of microfluidic devices for the production of small molecules, therapeutic proteins, and cells.

Previous $M B R$ research using a microbubble column bioreactor $(\mu B C)$ was performed by Peterat et al. (Peterat et al., 2014) and Krull and Peterat (Krull and Peterat, 2016) with the development and validation of a PDMS-glass-based $\mu B C$ manufactured by soft lithography technology. Lladó Maldonado et al. (Lladó Maldonado et al., 2018) developed a borosilicate glass-based $\mu B C$ manufactured by powder blasting and wet etching technology. The active aeration of both $\mu B C$ s allowed proper aeration of the cultivation broth, while ensuring its homogenization and preventing cell sedimentation. These $\mu B C$ s were equipped with online sensors for optical density $(O D)$ and dissolved oxygen $(D O)$ using a microneedle oxygen sensor.

The monitoring of biotechnological key process variables, e.g., carbon source concentration, biomass growth behavior, and product formation, provides essential information for biotechnological process characterization. The online monitoring of these parameters offers real-time analysis and process control and requires no sampling, which reduces the risk of process contamination and undisrupted flow. Conventional lab-scale bioreactors (with reaction volumes of 0.25 to $5 \mathrm{~L}$ ) are usually fully equipped with sensors, but when down-scaling to $M B R$ s the integration of sensors becomes less practical and challenging.

Optical chemical sensors are an attractive format for integration into microfluidic devices due to the following features: they are highly sensitive, inexpensive, and easy to miniaturize; and they are capable of non-invasive and non-destructive monitoring during operation (Ehgartner et al., 2016; Gruber et al., 2017b). Several reviews are published on the integration and application of optical sensor in microfluidic devices (Gruber et al., 2017a; Pfeiffer and Nagl, 2015; Sun et al., 2015). Alternatively, electrochemical biosensors provide an attractive option for the analysis of biological sample content due to their direct conversion of a biological response to a quantifiable and processable electronic signal. The advantages of electrochemical biosensors include their robustness, easy miniaturization, and excellent detection limits even with small analyte volumes, as well as their ability to be used in turbid cultivation broths with optically absorbing and fluorescing compounds (Grieshaber et al., 2008).

This article is protected by copyright. All rights reserved. 
To further develop the $\mu B C$ concept, this paper presents a novel disposable, fully online sensor-equipped $\mu B C$ (with a working volume of $550 \mu \mathrm{L}$ ) with highthroughput potential due to its versatility to be used in parallel and automated, as a screening platform for biotechnological research purposes. This work describes its design, fabrication and mixing and oxygen transfer characteristics as well as the integration of miniaturized optical and electrochemical sensors, which allow for the real-time online monitoring of the main cultivation process parameters, including the $O D, D O, p H$, and glucose concentration. As a demonstration, example batch cultivations of Saccharomyces cerevisiae were performed. Validation through these batch cultivations proved the long-term functionality of the sensors and reactor and established that process variable evolution could be observed over time.

\section{Materials and Methods}

\subsection{Microbioreactor design and manufacturing}

The $\mu B C$ was based on a semi-micro cuvette made of polystyrene (BR759015, Brand, Wertheim, Germany) that was vertically cut in half through the xy plane. A poly(methyl meth-acrylate) (PMMA) microscope slide (MS50510415, Labor-und Medizintechnik, Dr. Jutta Rost, Leipzig, Germany) was used to close the vertical open side of the $\mu B C$. A modified needle (Sterican, B. Braun Melsungen AG, Melsungen, Germany) with an outer diameter of $600 \mu \mathrm{m}$ and an inner diameter manually reduced to less than $100 \mu \mathrm{m}$ was inserted and sealed at the bottom of the cuvette, which served as a nozzle for the air supply. The $\mu B C$ consisted of a reaction chamber (4 mm width, $5 \mathrm{~mm}$ depth, and $20 \mathrm{~mm}$ height) and a funnel at the upper part (10 mm width, $5 \mathrm{~mm}$ depth, and $25 \mathrm{~mm}$ height) to ensure an adequate gas/liquid phase separation giving a total volume of $1.5 \mathrm{~mL}$. The $\mu B C$ was filled with cultivation medium up to the outlet level, giving a final reaction volume of approximately $550 \mu \mathrm{L}$ (Figure 1 and Figure 2).

The experiments were performed in a custom-made incubation chamber (450 $\mathrm{mm} \times$ $750 \mathrm{~mm} \times 450 \mathrm{~mm}$ ) that had temperature control and a heating and cooling system, as described in Peterat et al. (Peterat et al., 2014) and Krull and Peterat (Krull and Peterat, 2016). To avoid evaporation, the air supplied through the nozzle was watersaturated. The air flow was realized through a bottle $(500 \mathrm{~mL})$ filled with $50 \%$ distilled water at a temperature of $30{ }^{\circ} \mathrm{C}$ to ensure that the air flow did not have a cooling effect on the liquid reaction.

\subsection{Sensors}

The $\mu B C$ was equipped with miniaturized optical and electrochemical sensors that allowed the real-time online monitoring of the $O D, D O, p H$, and glucose concentration. Except for the $O D$ sensor, all the sensors were in contact with the media but did not interfere with the cells or media. In this work, $D O$ and $p H$ were measured through optical chemical sensors by means of lifetime-based measurements. The glucose concentration was measured using a glucose oxidase

This article is protected by copyright. All rights reserved. 
(GOx) enzyme electrochemical biosensor that was integrated into a two-dimensional microfluidic flow chip that extended the linear range. Optical density

The $O D$ of the biomass, which was measured at $600 \mathrm{~nm}\left(O D_{\mu B C}\right)$ during cultivation, was determined online using an LED panel (EA LG40X21-A green-yellow, 51 x 21.2 x $4.8 \mathrm{~mm}, 8 \mathrm{~V}$, Electronic Assembly, Gilching, Germany) and a miniature spectrometer (USB 2000+, Ocean Optics, Ostfildern, Germany) was coupled to an optical fiber (200 $\mu$ m diameter, M24L05, Thorlabs, Dachau, Germany). The $O D_{\mu B C}$ data $\left(O D_{\mu B C}=\ln \left(I_{0} / I\right)\right.$, where $I_{0}$ and $I$ are the light intensity measured through the reference and cell suspension) was continuously measured every second and an average of ten monitoring points was recorded every $10 \mathrm{~s}$.

A correlation between $O D_{\mu B C}$ and optical density measured offline in the spectrophotometer $\left(O D_{\text {photo }}\right)$ needed to be determined for every cultivation. A linear correlation could be adjusted with three pairs of $O D$ measurements data (media, inocula and final) and that enabled the conversion of $O D_{\mu B C}$ to $O D_{\text {photo. }}$

The correlation between the $O D_{\text {photo }}$ and biomass concentration, determined as the cell dry weight $(C D W)$ concentration here referred as $c_{X}(\mathrm{~g} / \mathrm{L})$ of $S$. cerevisiae, was derived from measurements of samples with known $C D W$ concentrations, as reported previously by Peterat (Peterat, 2014)

$$
c_{X}=0.3743 \cdot O D_{\text {photo }}
$$

\section{Dissolved oxygen and $\mathrm{pH}$}

$D O$ concentration measurements were carried out by integrating oxygen sensor spots on the inside of the microscope slide that closed the vertical back side of the $\mu B C$. First, a primary layer of the polymer HydroMed D4 hydrogel (AdvanSource Biomaterials Corp., Wilmington, Massachusetts, USA) dissolved in a mixture of tetrahydrofuran (THF) and toluene was microdispensed onto the $\mu B C$ walls to improve the adhesion of the $D O$ sensor spots. The oxygen sensor cocktail was prepared by dispersing oxygen sensitive particles in D4 hydrogel dissolved in isopropanol and water mixture. The particles were prepared according to Nacht et al. (Nacht et al., 2015) by polymerization and afterward stained with an oxygen sensitive dye, platinum(II) meso-tetra(4-fluorophenyl)tetrabenzoporphyrin (PtTPTBPF).

$p H$ sensor spots were micordispensed onto the microscope slide of the $\mu B C$. Similar to the oxygen sensor spots, a primary layer of polymer HydroMed D4 hydrogel dissolved in toluene was first spread on the polymeric slide to improve the adhesion of the sensor spots. The $p H$ sensor cocktail was prepared by dissolving the $p H$ indicator aza-BODIPY in D4 hydrogel in THF and water and adding Egyptian Blue reference particles, subsequently. $p H$ sensitive aza-BODIPY dye (4-(7-(3,5-dichloro4-hydroxyphenyl)-5,5-difluoro-1,9-diphenyl-5H-5 $\lambda^{4}, 6 \lambda^{4}$-dipyrrolo[1,2-c:2',1'f][1, 3,5,2] triazaborinin-3-yl)-N-dodecylbenzamid) was synthesized in-house according to Strobl et al. (Strobl et al., 2015). Egyptian blue reference particles $\left(\mathrm{CaCuSi}_{4} \mathrm{O}_{10}\right)$ were produced according to Borisov et al. (Borisov et al., 2013). The composition of the 
sensor cocktails as well as that of the primary layer used for microdispensing is described in Table 1.

The microdispenser (MDS 3200A, VERMES Microdispensing GmbH, Otterfing, Germany) was mounted on a three-axis Computerized Numerical Control machine (assembled in-house) run by the freeware LinuxCNC. The guiding programs for dispensing were written in G-Code. The microdispensing device worked with a piezoelectrically guided tappet that "shot" fluid drops (in this case polymer solutions) through a nozzle. The cocktail reservoir was sealed from the outside and under pressure. Adequate layer thickness was verified by checking the signal intensity of the spot.

Oxygen and $\mathrm{pH}$ sensor spots were read-out with a four-channel phase-shift fluorimeter FireStingO2 (PyroScience, Aachen, Germany) and a one-channel phaseshift fluorimeter Piccolo2 (PyroScience, Aachen, Germany). These instruments were used for luminescence lifetime-based measurements in the frequency domain. Dual lifetime referencing was applied for $\mathrm{pH}$ sensors as reported by Jokic et al. (Jokic et al., 2012) and Borisov et al. (Borisov et al., 2013). A custom-made holder made of polycarbonate was used to hold and fix these fibers at their same positions throughout the experiments. The optical fibers (tip diameter $1 \mathrm{~mm}$ ) were directed to the outer surface of the $\mu B C$, where they were guided through access holes in the chip holder and connected to FireStingO2 for the online oxygen monitoring spot and to Piccolo2 for the online $\mathrm{pH}$ monitoring spot. Both the $\mathrm{DO}$ and $\mathrm{pH}$ data were continuously measured and recorded every $10 \mathrm{~s}$ from an average of three measurements using Pyro Oxygen Logger software (PyroScience, Aachen, Germany).

Calibration data for the oxygen sensor spot were similar to reported in Nacht et al. (Nacht et al., 2015). The oxygen sensors were calibrated via a two-point calibration. The $\mu B C$ was filled with cultivation media and then flushed with air and $N_{2}$, respectively to determine the phase shift (dphi) at air-saturated and deoxygenated conditions. To calibrate the $\mathrm{pH}$ sensor spot, 5 solutions of cultivation media were adjusted to different $p H$ values $(p H=1.85,3.25,3.95,4.71$ and 6.39$)$ by adding $H C l$ or $\mathrm{NaOH}$, the $\mathrm{pH}$ of which were measured by a $\mathrm{pH}$ electrode (BlueLine $16 \mathrm{pH}$, SI Analytics, Weilheim, Germany) and a pH meter (CG840, Schott-Geräte, Mainz, Germany). Each of these calibration solutions were used to fill the $M B R$, and the phase shifts were recorded. The calibration environment (e.g., temperature, aeration, and light) was the same as that of the cultivation conditions, and the calibrations were performed by measuring the dphi values. A Boltzmann curve was fitted to the calibration points (cotangent of the $d p h i$ values with respect to the $p H$ ) with OriginPro 2015 (OriginLab Corporation, Northampton, Massachusetts, USA). The dynamic range of the sensor was from $\sim 2.5$ to 5.5 (Supplementary material).

\section{Glucose sensor}

Glucose, the limiting carbon source consumed by the cultivated cells, normally requires sampling and bacterial removal to measure its concentration off-line; however, here, it was measured online using an electrochemical biosensor integrated

This article is protected by copyright. All rights reserved. 
in an adjacent microfluidic chip as sampling was not possible because of the small $M B R$ volume.

Carbon substrate (glucose) depletion was monitored by a glucose biosensor based on a glucose oxidase enzymatic electrochemical biosensor, as reported in Panjan et al. (Panjan et al., 2017b). The sensor consisted of screen-printed electrodes (3-mm diameter graphite working electrode, graphite counter electrodes and sliver reference electrode) (ECOBIO lab, Florence, Italy) modified with a layer of immobilized GOx from Aspergillus niger VII S (195 U/mg) (E.C. 1.1.3.4) as the catalytic biological recognition element. Prussian blue $(P B)$ was used to modify the surface of the working electrode to perform as a redox mediator. The hydrogen peroxide produced by $G O x$ caused a selective electrocatalytic reaction with $P B$. The current was measured by amperometric detection using a potentiostat (PalmSens, Houten, The Netherlands). The amperometric signal which directly correlates to the concentration of glucose in the bulk solution was used for the quantification of glucose.

Amperometric measurements were calibrated via known concentrations of glucose in the cultivation broth (at the beginning and at the end of the cultivation).

The glucose biosensor was integrated into a PMMA microfluidic chip that was fabricated using a $\mathrm{CO}_{2}$-laser and bonded using double-sided medical grade $100-\mu \mathrm{m}$ thick adhesive (Adhesive Research, Limerick, Ireland). The biosensor integration chip featured an microfluidic loop that allowed an internal buffer (phosphate buffer saline, $P B S$ ) to flow using a precision syringe pump (Nemesys, Cetoni GmbH, Korbussen, Germany) between the integrated semipermeable membrane (contact area $12 \mathrm{~mm}^{2}$, cut-off molecular weight 6-8 kDa, Spectrum Laboratories Inc., Rancho Dominguez, California, USA) and the downstream integrated glucose biosensor. The microfluidic flow chip was mounted onto the backside of the microscope slide and integrated into the $\mu B C$ via a drilled hole (3.5 mm in diameter), such that the semipermeable membrane was in contact with the cultivation broth. Only molecules as small as glucose could diffuse through the membrane. The microfluidic flow chip extended the concentration range of glucose detection by working as a dilution unit of the bulk solution, depending on the chosen diffusion time. The glucose biosensor had a limit of detection of $0.006 \mathrm{mM}(1 \mathrm{mg} / \mathrm{L})$, with a linear range of up to $3 \mathrm{mM}$ (5.4 mg/L) (Panjan et al., 2017b).

A stopped-flow protocol was used for the measurement of glucose. The integrated microfluidic flow chip buffer flow was stopped for 7.5 min (diffusion time) to allow glucose to diffuse from the $M B R$ into the buffer underneath the semipermeable membrane. After the diffusion time, the flow was turned on again for $1.5 \mathrm{~min}$ (flow rate $1.67 \mu \mathrm{L} / \mathrm{s}$ ), and the glucose concentration in the buffer could flow to the other side of the membrane and be measured when it was in contact with the glucose sensor. 2.3 Microbioreactor characterization

The mixing time with $95 \%$ homogeneity criteria $\theta_{95}$ was characterized for different air volume flow rates between 4.1 to $12.8 \mu \mathrm{L} / \mathrm{s}$ at times ranging from 3 to $1 \mathrm{~s}$.

Sequence of images were captured immediately after the injection of a fluorescent

This article is protected by copyright. All rights reserved. 
tracer pulse $(5 \mu \mathrm{L})$ through a precision syringe pump (Nemesys, Cetoni GmbH, Korbussen, Germany) with a frame rate of $3.3 \mathrm{fps}$.

The mixing time $\theta_{95}$ was based on the time profile of the variation in the average color pixel intensity in the vertical surface of the $\mu B C$ after the introduction of the fluorescent tracer solution, as reported by Lladó Maldonado et al. (Lladó Maldonado et al., 2018). The acquired pictures and frames were transformed into $R G B$ format with ImageJ (ImageJ 1.49v, National 211 Institutes of Health, Bethesda, Maryland, USA), and therefore, the average color pixel intensity was obtained as a combination of the intensities of the red, green and blue channels. The green channel was selected and normalized to determine $\theta_{95}$.

The volumetric liquid-phase mass transfer coefficient $\left(k_{L} a\right)$ was measured by the dynamic gassing-out method. For every $k_{L} a$ measurement, oxygen was removed from the cell-free cultivation media by gassing nitrogen into the $\mu B C$ until the oxygen concentration was equal to zero. Then, the nitrogen supply was turned off, and the reactor was aerated. $k_{L} a$ values were calculated from the increase in $D O$ over time. The air flow was determined using a custom-made U-tube manometer as reported in Peterat et al. (Peterat et al., 2014). The $k_{L} a$ values depended on the air flow supplied. The airflow rate and superficial gas velocity achieved with an applied pressure of 2 bar were $12.8 \mu \mathrm{L} / \mathrm{s}$ and $6.4 \cdot 10^{-4} \mathrm{~m} / \mathrm{s}$, respectively. These conditions were used for the cultivations.

\subsection{Cultivation of Saccharomyces cerevisiae}

For validation purposes, batch cultivations in the $\mu B C$ with the sensors were performed using the well-described and investigated Crabtree-positive $S$. cerevisiae strain CCOS 538 (ATCC 32167, Culture Collection of Switzerland) (Beck and von Meyenburg, 1968; Kuhlmann et al., 1984; Rieger et al., 1983; Sonnleitner and Käppeli, 1986). The cultivations were performed at $30^{\circ} \mathrm{C}$ with a chemically defined cultivation medium (Edlich et al., 2010; Krull and Peterat, 2016; Peterat et al., 2014), an initial glucose concentration of $20 \mathrm{~g} / \mathrm{L}$ and an initial $\mathrm{pH}$ value of 4.35 .

Inocula of S. cerevisiae CCOS 538 were prepared from a cryo-culture stored with glycerol at $-80^{\circ} \mathrm{C}$. The cells were reactivated by growing them overnight in roundbottom, sterile plastic cell culture tubes at $30^{\circ} \mathrm{C}$ and shaking at $1801 / \mathrm{min}$, and the cultures were then diluted to an $O D_{600}$ of 0.3 (Spectrophotometer Libra S 11, Biochrom, Cambridge, UK) using deionized water as the reference. To measure $O D$ values within the linear range $(0.1 \leq O D \leq 0.45)$, the samples were diluted using deionized water when necessary.

The oxygen content inside the $\mu B C$ is the result of the continuous oxygen transfer from the air bubbled into the cultivation medium (OTR) and the oxygen consumption by the cells growing inside the medium (OUR).

$$
\frac{d c_{L}}{d t}=O T R-O U R
$$

This article is protected by copyright. All rights reserved. 


$$
\begin{aligned}
& \text { OTR }=k_{L} a \cdot\left(c_{L}^{*}-c_{L}\right) \\
& \text { OUR }=\operatorname{sOUR} \cdot c_{X}
\end{aligned}
$$

where $k_{L} a$ is the volumetric liquid-phase mass transfer coefficient, $c_{L}{ }^{*}$ is the oxygen saturation concentration $\left(0.235 \mathrm{mmol} / \mathrm{L}\right.$ at $\left.30{ }^{\circ} \mathrm{C}\right)$, and $c_{L}$ is the $D O$ concentration in the liquid phase. $c_{X}$ is the biomass concentration and $s O U R$ the specific $O U R$.

To supply sufficient oxygen to the cells and to avoid oxygen depletion, the maximum OTR $\left(O T R_{\text {max }}\right)$ (estimated by the product $\left.k_{L} a \cdot c_{L}{ }^{*}\right)$ must be bigger than the OUR. The OUR was determined from the OTR by using the previously determined $k_{L} a$ (Section 2.3) and the $D O$ profile in the liquid phase measured during the course of the cultivation and the values of the derivative of $D O$ versus time curve (Garcia-Ochoa et al., 2010). OUR during the process could be obtained from equation 5

$$
\text { OUR }=k_{L} a \cdot\left(c_{L}^{*}-c_{L}\right)-\frac{d c_{L}}{d t}
$$

\section{Results and Discussion}

\subsection{Sensor integration and calibration}

The integration of optical chemical sensors for $D O$ and $p H$ monitoring was realized as follows. The oxygen and $\mathrm{pH}$ sensor spots were dispensed on a microscope slide as described in Section 2.2 (Figure 3A). The microscope slide was then glued to a half cuvette. Subsequently, a hole was drilled into the backside of the $M B R$, and the electrochemical glucose sensor (Figure 3B), which was previously integrated into a microfluidic flow chip (Figure 3C), was attached, fixing the membrane area to the created hole.

The oxygen sensor spots were calibrated via a simple two-point calibration. For the $\mathrm{pH}$ sensor spots, a 5-point calibration was carried out with cultivation media adjusted to different $p H$ values as mentioned in Section 2.2.

A linear correlation between the glucose concentration and the current measured by the PalmSens potentiostat was proven for concentrations of up to $0.5 \mathrm{~g} / \mathrm{L}$ in Panjan et al. (Panjan et al., 2017a). In the current work, higher concentrations of glucose could be measured due to the tunable dynamic range offered by the adjustment of the microfluidic flow chip diffusion time and buffer flow rate. Figure 4 shows the current signal with different diffusion times; the current signal value was larger when longer diffusion times were applied because more glucose molecules could diffuse. For cultivations using a glucose concentration of $20 \mathrm{~g} / \mathrm{L}$, a diffusion time of $7.5 \mathrm{~min}$ and a flow time of $1.5 \mathrm{~min}$ at $100 \mu \mathrm{L} / \mathrm{min}$ of PBS buffer were used. The glucose sensors required daily calibration because the GOx activity varied; however, a 2-point calibration was performed, which proved to be very suitable for this application.

This article is protected by copyright. All rights reserved. 


\section{2 $\mu \mathrm{BC}$ characterization}

One of the challenges of $M B R$ s is achieving short mixing times. Mixing under laminar flow conditions occurs by diffusion. In the $\mu B C$, the rising bubbles induce circular convection in the liquid due to drag forces and thus enhance mixing by reducing diffusion distances and preventing cell sedimentation. The bubble-induced convection ensures adequate mixing performance. Figure 5 shows an example sequence of images captured immediately after the injection of a fluorescent tracer pulse through a precision syringe pump. As described in Section 2.3 the mixing time with was characterized to range from 3 to $1 \mathrm{~s}$, which are very fast mixing times compared to other MBRs or miniaturized systems: from 13 down to $5.5 \mathrm{~s}$ in the glass$\mu B C$ (Lladó Maldonado et al., 2018); between 15 and $2 \mathrm{~s}$ in the PDMS- $\mu B C$ (Peterat, 2014); mixing times of $\sim 7 \mathrm{~s}$ (Kirk et al., 2016); between 20 and $5 \mathrm{~s}$ in a miniaturized $10 \mathrm{~mL}$ stirred tank bioreactor (Betts et al., 2006).

Among the parameters measured to characterize the functionality of the $M B R$ were the air flow rate (together with the superficial liquid velocity) and $k_{L} a$. The $k_{L} a$ was measured in triplicate via the dynamic gassing-out method (Figure 6) using the air flow rate applied during cultivation, resulting in a value of $2041 / \mathrm{h}$ with an $O T R_{\max }$ of $48 \mathrm{mmol} /(\mathrm{L} \cdot \mathrm{h})$. These values were comparable to the $k_{L} a$ values of other $M B R \mathrm{~s}$ or miniaturized systems described in literature (Bolic et al., 2016; Doig et al., 2005a; Doig et al., 2005b; Kheradmandnia et al., 2015; Kirk et al., 2016; Lladó Maldonado et al., 2018; Peterat et al., 2014; Weuster-Botz et al., 2001)

\subsection{Cultivation in the $\mu \mathrm{BC}$}

A batch cultivation of the model microorganism $S$. cerevisiae was performed as a test for the applicability of the fully equipped with sensors $\mu B C$. S. cerevisiae was cultivated in the $\mu B C$ with an initial $O D_{600}$ of 0.3 as described in Section 2.4. With the implemented sensor system, monitoring the changes in 1) glucose concentration, 2) $C D W$ concentration through the determination of the $O D$, 3) $p H$, and 4) $D O$ was possible over the entire cultivation time.

In Figure 7, the averaged growth of S. cerevisiae over time of two independent cultivation replicates with the respective standard deviations is presented. After an initial lag phase (cultivation time $0-1 \mathrm{~h}$ ), there was a phase of exponential growth on glucose $(1-10 \mathrm{~h})$, a second lag phase due to the adaptation of $S$. cerevisiae to the metabolic products generated $(10.5-12.5 \mathrm{~h})$, a subsequent post-diauxic phase (12.5 $19 \mathrm{~h}$ ) in which the generated metabolic products served as carbon sources and a final stationary phase (from $19 \mathrm{~h}$ ). In the first growth phase, S. cerevisiae utilized glucose as a carbon source and produced acids and ethanol; later, in the subsequent growth phase, when glucose was depleted (or at a low concentration), the ethanol that had accumulated served as a substrate for further growth of the cells. This diauxic 
behavior was observed at $10.5 \mathrm{~h}$ of cultivation and, from a metabolic point of view, can be explained by the switch of the main carbon source from glucose to ethanol. During this second lag phase, the organism adapted to changes in the cultivation conditions by synthesizing new enzymes to consume the metabolites that were generated (Jones and Kompala, 1999). This behavior has been reported by Sonnleitner and Käppeli (Sonnleitner and Käppeli, 1986) and was recently described by Bisschops et al. (Bisschops et al., 2015).

This hypothesis was confirmed by monitoring the changes in the glucose concentration and $\mathrm{pH}$. The glucose concentration in the medium at the beginning of cultivation was $20 \mathrm{~g} / \mathrm{L}$, and the $p H$ was 4.34 . After $9 \mathrm{~h}$ of cultivation, the glucose was totally consumed, and therefore, no glucose was available for further cell growth. At $10 \mathrm{~h}$, cell growth slowed down, and at $11.5 \mathrm{~h}$, the $p H$ stopped decreasing $(p H=4.17)$. During the first $11 \mathrm{~h}$ of cultivation, S. cerevisiae produced acidic metabolites, e.g., acetate, which accumulated in the medium, causing the $p H$ to decrease. After $10 \mathrm{~h}$ of cultivation, because glucose, the preferred carbon source, was exhausted, the cells started utilizing the acids and other previously generated carbon sources for further growth, which explains the increase in $p H$ to 4.22 at the end of cultivation. At $17 \mathrm{~h}$ of cultivation, cell growth slowed again, most likely due to the total consumption of generated metabolites during the first phase, indicating the beginning of the final stationary phase. The acidification of the extracellular medium by yeast cultures has been reported previously (Castrillo et al., 1995; Sigler et al., 1981a; Sigler et al., 1981b). In this case, the alteration in the $p H$ tendency was most likely influenced by metabolic pathway changes because they occurred simultaneously with the end of the glucose-based growth phase and the start of the ethanol-based growth phase.

During the glucose phase, the maximum specific growth rate was estimated to be 0.35 1/h, reaching a final $C D W$ concentration of $3 \mathrm{~g} / \mathrm{L}$, which corresponds to a cell mass yield of $0.15 \mathrm{~g}_{\mathrm{CDW}} / \mathrm{g}_{\mathrm{Glucose}}$. During the post-diauxic phase, the maximum growth rate from ethanol oxidation was $0.131 / \mathrm{h}$, which is threefold lower than that during fast growth on glucose, and a final $C D W$ of $5.7 \mathrm{~g} / \mathrm{L}$; the cell mass yield could not be determined due to the absence of ethanol measurements. Growth in the post-diauxic phase in which metabolism is completely respiratory is slower than that of the preceding glucose phase (Sonnleitner and Käppeli, 1986).

The value for the specific growth rates of $S$. cerevisiae on glucose $(0.351 / \mathrm{h})$ and on ethanol $(0.13 \mathrm{1} / \mathrm{h})$ are comparable to values reported in the literature for aerobic batch cultivations. For cultivations in stirred and aerated bioreactors in the bench-scale were reported specific growth rates of 0.39 1/h and $0.101 / \mathrm{h}$ (Bisschops et al., 2015), 0.42 and 0.14 1/h (Beck and von Meyenburg, 1968), 0.40 1/h and 0.13 1/h (Kuhlmann et al., 1984), respectively. At the microliter-scale, in a $\mu B C$, a specific growth rate on glucose of 0.37 1/h (Peterat et al., 2014). Although the volumes and initial substrate concentrations were different in all these cases $(10-30 \mathrm{~g} / \mathrm{L}$ glucose), the specific growth rate values determined using the $\mu B C$ were roughly the same as those published from laboratory scale experiments, thus validating the applicability of the current $\mu B C$ as a suitable screening tool for aerobic submerged cultivations.

This article is protected by copyright. All rights reserved. 
Due to the high specific oxygen demand of the cells, the $D O$ decreased then reached a plateau at the end of the growth, after which it was observed to increase again to the saturation level (data not shown in the graphic). The $D O$ level remained high (above $50 \%$ air saturation) during the whole cultivation period, confirming that sufficient aeration for cultivation can be ensured by the active aeration of the $\mu B C$ and that no oxygen limitation occurred during cultivation. Due to the small cultivation volume, pneumatic-induced aeration was a powerful and simple way to achieve sufficient oxygen supply for cultivation. The OUR was calculated from the variance in $D O$ together with the determined $k_{L} a$ (estimated to be constant during the cultivation) (equation 5). The OUR during the predominantly fermentative glucose-based growth phase started at a low, non-zero value due to the relatively low-level activity of the glucose oxidative pathway. At the end of the glucose-based growth phase, the OUR increased briefly because, for a short period, the glucose oxidative pathway was preferred.

During the diauxic lag phase, the key enzymes required to catalyze the ethanol oxidative pathway were synthetized, allowing $S$. cerevisiae to subsequently consume the ethanol produced during the first growth phase. The OUR increased substantially during the ethanol-based growth phase, which fits with the oxidative nature of the pathway. In the final stationary phase, the OUR decreased because the metabolic activity of the cells decreased (not shown in the graphic). These observations were in good accordance to Otterstedt et al. (Otterstedt et al., 2004), which investigated the metabolism of S. cerevisiae.

The specific OUR (sOUR) is characteristic for each microorganism and is usually considered constant during microbial growth on a certain carbon source (GarciaOchoa et al., 2010). The $O U R$ values increased linearly in proportion to the $C D W$ concentration (Figure 8). During the glucose-based growth phase, the sOUR was 2.0 $-2.5 \mathrm{mmol} \mathrm{O}_{2} /\left(\mathrm{g}_{\mathrm{CDw}} \cdot \mathrm{h}\right)$, while during the ethanol-based growth phase, it was 2.5 $4.5 \mathrm{mmol} \mathrm{O} /\left(\mathrm{g}_{\mathrm{CDw}} \cdot \mathrm{h}\right)$. The $s O U R$ in the second growth phase was higher because the metabolism of ethanol is oxidative, while during the glucose-based growth phase, the glucose fermentative pathway is preferred. The values of the $s O U R$ were similar to values reported in the literature: $1.3-1.5 \mathrm{mmol} \mathrm{O}_{2} /\left(\mathrm{g}_{\mathrm{CDW}} \cdot \mathrm{h}\right)$ in the glucose-based growth phase (Peterat et al., 2014) and from $2-12 \mathrm{mmol} \mathrm{O} /\left(\mathrm{g}_{\mathrm{CDw}} \cdot \mathrm{h}\right)$ (von Meyenburg, 1969b) and 3 to $9 \mathrm{mmol} \mathrm{O}_{2} /\left(\mathrm{g}_{\mathrm{CDw}} \cdot \mathrm{h}\right)$ (Kuhlmann et al., 1984) for the glucose and ethanol-based growth phases, respectively. Higher sOUR values have been reported under continuous cultivation conditions, with a maximum sOUR of up to $8.25 \mathrm{mmol} \mathrm{O}_{2} /\left(\mathrm{g}_{\mathrm{CDW}} \cdot \mathrm{h}\right)$ achieved when the dilution rate occurred at the onset of aerobic ethanol formation (von Meyenburg, 1969a; Rieger et al., 1983; Sonnleitner and Käppeli, 1986).

\section{Conclusions}

In the present work, a novel, fully sensor-integrated $M B R$ was developed. The design of the $M B R$ was optimized from previous work, and a rapid disposable custom-made version of the reactor was built. The in-house construction allowed for on-demand production, with flexibility in the reactor volume, sensor disposition, and inlet and

This article is protected by copyright. All rights reserved. 
outlet location, thus making the screening process faster and cheaper. Owing to the optimal design, the $O D, D O, p H$ and glucose sensors were easily integrated into the $M B R$ system. The $\mu B C$ showed sufficient aeration characteristics and fast mixing performance due to the stream of bubbles that rises through the vertical device.

Process monitoring and control is important for biotechnology applications and become challenging in small-scale reactor systems that offer limited space and sample volumes. Here, a sensing strategy for the integration of optical and biochemical sensors into a $\mu B C$ for bioprocess analysis is presented. For the first time, multiple online sensing systems were implemented in a small reactor to obtain important parameters during cultivation. The resulting integrated $\mu B C$ setup allowed the online monitoring of $\mathrm{DO}, \mathrm{pH}$, glucose concentration and $\mathrm{OD}$ during batch cultivation, which was demonstrated by monitoring the typical diauxic growth behavior of a Crabtree-positive $S$. cerevisiae strain. These parameters provide valuable information on cell cultivation kinetics; moreover, they validate the usage of the $\mu B C$ as a microscreening tool because the same growth characteristics were obtained with bioreactors at the conventional liter scale. The real-time, inline monitoring also enables process control in future work, for example, $p H$ control by adding acid or base, substrate addition or $D O$ control by adjusting the air flow rate.

The developed $\mu B C$ demonstrated all the necessary features for autonomous, inexpensive cultivation and showed potential for online analytics and parallelization. The long-term operational constitution of the sensors and reactor was demonstrated, as was the ability to observe process variable evolution over time. Moreover, the $\mu B C$ is amenable to modification for working in batch, fed-batch or continuous mode, which offers much potential for biotechnological research and development. With a better understanding of microorganisms and their reactions in the $\mu B C$, as well as the reactor itself, biotechnology at the microscale appears very promising.

\section{Acknowledgements}

The authors gratefully acknowledge the financial support provided by the People Programme (Marie Curie Actions, Multi-ITN) of the European Union's Seventh Framework Programme for research, technological development and demonstration within the project EUROMBR - European network for innovative microbioreactor applications in bioprocess development (Project ID 608104). The authors thank Hendrik Ostsieker, B. Sc., for his valuable assistance with the technical drawings.

\section{Declaration of interest}

The authors declare that they have no competing interests.

This article is protected by copyright. All rights reserved. 


\section{References}

Beck C, von Meyenburg HK. 1968. Enzyme pattern and aerobic growth of Saccharomyces cerevisiae under various degrees of glucose limitation. $J$. Bacteriol. 96:479-486.

Betts JI, Doig SD, Baganz F. 2006. Characterization and application of a miniature 10 $\mathrm{mL}$ stirred-tank bioreactor, showing scale-down equivalence with a conventional 7 L reactor. Biotechnol. Prog. 22:681-688.

Bisschops M, Vos T, Martinez-Moreno R, de la Torre Cortes P, Pronk J, DaranLapujade P. 2015. Oxygen availability strongly affects chronological lifespan and thermotolerance in batch cultures of Saccharomyces cerevisiae. Microb. Cell 2:429-444.

Bolic A, Larsson H, Hugelier S, Eliasson Lantz A, Krühne U, Gernaey K V. 2016. A flexible well-mixed milliliter-scale reactor with high oxygen transfer rate for microbial cultivations. Chem. Eng. J. 303:655-666.

Borisov SM, Würth C, Resch-Genger U, Klimant I. 2013. New life of ancient pigments: Application in high-performance optical sensing materials. Anal. Chem. 85:9371-9377.

Castrillo JI, De Miguel I, Ugalde UO. 1995. Proton production and consumption pathway in yeast metabolism. A chemostat culture analysis. Yeast 11:13531365.

Demming S, Peterat G, Llobera A, Schmolke H, Bruns A, Kohlstedt M, Al-Halhouli A, Klages C-P, Krull R, Büttgenbach S. 2012. Vertical microbubble column-A photonic lab-on-chip for cultivation and online analysis of yeast cell cultures. Biomicrofluidics 6:34106.

Doig SD, Diep A, Baganz F. 2005a. Characterisation of a novel miniaturised bubble column bioreactor for high throughput cell cultivation. Biochem. Eng. J. 23:97105.

Doig SD, Ortiz-Ochoa K, Ward JM, Baganz F. 2005b. Characterization of oxygen transfer in miniature and lab-scale bubble column bioreactors and comparison of microbial growth performance based on constant $k_{L} a$. Biotechnol. Prog. 21:1175-1182.

Edlich A, Magdanz V, Rasch D, Demming S, Aliasghar Zadeh S, Segura R, Kähler C, Radespiel R, Büttgenbach S, Franco-Lara E, Krull R. 2010. Microfluidic reactor for continuous cultivation of Saccharomyces cerevisiae. Biotechnol. Prog. 26:1259-1270.

This article is protected by copyright. All rights reserved. 
Ehgartner J, Sulzer P, Burger T, Kasjanow A, Bouwes D, Krühne U, Klimant I, Mayr T. 2016. Online analysis of oxygen inside silicon-glass microreactors with integrated optical sensors. Sensors Actuators B Chem. 228:748-757.

Garcia-Ochoa F, Gomez E, Santos VE, Merchuk JC. 2010. Oxygen uptake rate in microbial processes: An overview. Biochem. Eng. J. 49:289-307.

Grieshaber D, MacKenzie R, Vörös J, Reimhult E. 2008. Electrochemical biosensors - Sensor principles and architectures 8:1400-1458.

Gruber P, Marques MPC, Szita N, Mayr T. 2017a. Integration and application of optical chemical sensors in microbioreactors. Lab Chip 17:2693-2712.

Gruber P, Marques MPC, Sulzer P, Wohlgemuth R, Mayr T, Baganz F, Szita N. 2017b. Real-time $\mathrm{pH}$ monitoring of industrially relevant enzymatic reactions in a microfluidic side-entry reactor ( $\mu$ SER) shows potential for $\mathrm{pH}$ control. Biotechnol. J. 12:1600475.

Hegab HM, Elmekawy A, Stakenborg T. 2013. Review of microfluidic microbioreactor technology for high-throughput submerged microbiological cultivation. Biomicrofluidics 7:21502.

Jokic T, Borisov SM, Saf R, Nielsen DA, Kühl M, Klimant I. 2012. Highly photostable near-infrared fluorescent $\mathrm{pH}$ indicators and sensors based on BF2chelated tetraarylazadipyrromethene dyes. Anal. Chem. 84:6723-6730.

Jones KD, Kompala DS. 1999. Cybernetic model of the growth dynamics of Saccharomyces cerevisiae in batch and continuous cultures. J. Biotechnol. 71:105-131.

Kheradmandnia S, Hashemi-Najafabadi S, Shojaosadati SA, Mousavi SM, Malek Khosravi K. 2015. Development of parallel miniature bubble column bioreactors for fermentation process. J. Chem. Technol. Biotechnol. 90:1051-1061.

Kirk T V, Szita N. 2013. Oxygen transfer characteristics of miniaturized bioreactor systems. Biotechnol. Bioeng. 110:1005-1019.

Kirk TV, Marques MPC, Radhakrishnan ANP, Szita N. 2016. Quantification of the oxygen uptake rate in a dissolved oxygen controlled oscillating jet-driven microbioreactor. J. Chem. Technol. Biotechnol. 91:823-831.

Krull R, Lladó Maldonado S, Lorenz T, Büttgenbach S, Demming S. 2016. Microbioreactors. In: Dietzel, A, editor. Microsystems Pharmatechnology. Manip. fluids, Part. droplets, cells. Cham Heidelberg New York Dordrecht London: Springer International Publishing, pp. 99-152.

Krull R, Peterat G. 2016. Analysis of reaction kinetics during chemostat cultivation of Saccharomyces cerevisiae using a multiphase microreactor. Biochem. Eng. J.

This article is protected by copyright. All rights reserved. 
105:220-229.

Kuhlmann W, Meyer H-D, Bellgardt KH, Schügerl K. 1984. On-line analysis of yeast growth and alcohol production. J. Biotechnol. 1:171-185.

Lattermann C, Büchs J. 2015. Microscale and miniscale fermentation and screening. Curr. Opin. Biotechnol. 35:1-6.

Lladó Maldonado S, Rasch D, Kasjanow A, Bouwes D, Krühne U, Krull R. 2018. Multiphase microreactors with intensification of oxygen mass transfer rate and mixing performance for bioprocess development. Biochem. Eng. J. DOI: 10.1016/j.bej.2018.07.023.

Marques MPC, Szita N. 2017. Bioprocess microfluidics : applying microfluidic devices for bioprocessing. Curr. Opin. Chem. Eng. 18:61-68.

von Meyenburg HK. 1969a. Energetics of the budding cycle of Saccharomyces cerevisiae during glucose limited aerobic growth. Arch. Mikrobiol. 66:289-303.

von Meyenburg K. 1969b. Katabolit-Repression und der Sprossungszyklus von Saccharomyces cerevisiae; PhD thesis, ETH Zürich.

Nacht B, Larndorfer C, Sax S, Borisov SM, Hajnsek M, Sinner F, List-Kratochvil EJW, Klimant I. 2015. Integrated catheter system for continuous glucose measurement and simultaneous insulin infusion. Biosens. Bioelectron. 64:102110.

Otterstedt K, Larsson C, Bill RM, Ståhlberg A, Boles E, Hohmann S, Gustafsson L. 2004. Switching the mode of metabolism in the yeast Saccharomyces cerevisiae. EMBO Rep. 5:532-537.

Panjan P, Ohtonen E, Tervo P, Virtanen V, Sesay AM. 2017a. Shelf life of enzymatic electrochemical sensors. Procedia Technol. 27:306-308.

Panjan P, Virtanen V, Sesay AM. 2017b. Determination of stability characteristics for electrochemical biosensors via thermally accelerated ageing. Talanta 170:331336.

Perozziello G, Møllenbach J, Laursen S, Di Fabrizio E, Gernaey K, Krühne U. 2012. Lab on a chip automates in vitro cell culturing. Microelectron. Eng. 98:655-658.

Peterat G. 2014. Prozesstechnik und reaktionskinetische Analysen in einem mehrphasigen Mikrobioreaktorsystem. Ed. Krull R. Göttingen: Cuvillier-Verlag. Vol. 75 103p. ibvt-Schriftenreihe, PhD thesis, TU Braunschweig.

Peterat G, Schmolke H, Lorenz T, Llobera A, Rasch D, Al-Halhouli AT, Dietzel A, Büttgenbach S, Klages C-P, Krull R. 2014. Characterization of oxygen transfer in vertical microbubble columns for aerobic biotechnological processes.

This article is protected by copyright. All rights reserved. 
Biotechnol. Bioeng. 111:1809-1819.

Pfeiffer SA, Nagl S. 2015. Microfluidic platforms employing integrated fluorescent or luminescent chemical sensors: a review of methods, scope and applications. Methods Appl. Fluoresc. 3:34003.

Rieger M, Käppeli O, Fiechter A. 1983. The role of limited respiration in the incomplete oxidation of glucose by Saccharomyces cerevisiae. J. Gen. Microbiol. 129:653-661.

Schäpper D, Alam MNHZ, Szita N, Lantz AE, Gernaey KV. 2009. Application of microbioreactors in fermentation process development: a review. Anal. Bioanal. Chem. 395:679-695.

Schäpper D, Stocks SM, Szita N, Lantz AE, Gernaey KV. 2010. Development of a single-use microbioreactor for cultivation of microorganisms. Chem. Eng. J. 160:891-898.

Sigler K, Kotyk A, Knotková A, Opekarová M. 1981a. Processes involved in the creation of buffering capacity and in substrate-induced proton extrusion in the yeast Saccharomyces cerevisiae. BBA - Biomembr. 643:583-592.

Sigler K, Knotková A, Kotyk A. 1981b. Factors governing substrate-induced generation and extrusion of protons in the yeast Saccharomyces cerevisiae. Biochim. Biophys. Acta - Biomembr. 643:572-582.

Sonnleitner B, Käppeli O. 1986. Growth of Saccharomyces cerevisiae is controlled by its limited respiratory capacity: Formulation and verification of a hypothesis. Biotechnol. Bioeng. 28:927-937.

Strobl M, Rappitsch T, Borisov SM, Mayr T, Klimant I. 2015. NIR-emitting azaBODIPY dyes - new building blocks for broad-range optical $\mathrm{pH}$ sensors. Analyst 140:7150-7153.

Sun S. 2017. Applications of integrated optical sensors for $\mathrm{pH}$ and oxygen monitoring in micro(bio)reactor; PhD thesis, Graz University of Technology.

Sun S, Ungerböck B, Mayr T. 2015. Imaging of oxygen in microreactors and microfluidic systems. Methods Appl. Fluoresc. 3:34002.

Szita N, Boccazzi P, Zhang Z, Boyle P, Sinskey AJ, Jensen KF. 2005. Development of a multiplexed microbioreactor system for high-throughput bioprocessing. Lab Chip 5:819-826.

Weuster-Botz D, Altenbach-Rehm J, Hawrylenko A. 2001. Process-engineering characterization of small-scale bubble columns for microbial process development. Bioprocess Biosyst. Eng. 24:3-11.

This article is protected by copyright. All rights reserved. 
Zanzotto A, Szita N, Boccazzi P, Lessard P, Sinskey AJ, Jensen KF. 2004.

Membrane-aerated microbioreactor for high-throughput bioprocessing.

Biotechnol. Bioeng. 87:243-254.

Zhang Z, Perozziello G, Boccazzi P, Sinskey AJ, Geschke O, Jensen KF. 2007.

Microbioreactors for Bioprocess Development. J. Assoc. Lab. Autom. 12:143151.

Zhang Z, Boccazzi P, Choi H-G, Perozziello G, Sinskey AJ, Jensen KF. 2006.

Microchemostat-microbial continuous culture in a polymer-based, instrumented microbioreactor. Lab Chip 6:906-913.

This article is protected by copyright. All rights reserved. 


\section{Figures}

Figure 1: (Left) Technical drawing of the $\mu B C$ (front side view) with the microfluidic flow chip for glucose measurement; the inlets and outlets of the liquid and gas phases, and the integrated sensors for $\mathrm{pH}$, dissolved oxygen and optical density. (Right) Technical drawing of the $\mu B C$ (back side view) with dimensions in $\mathrm{mm}$.
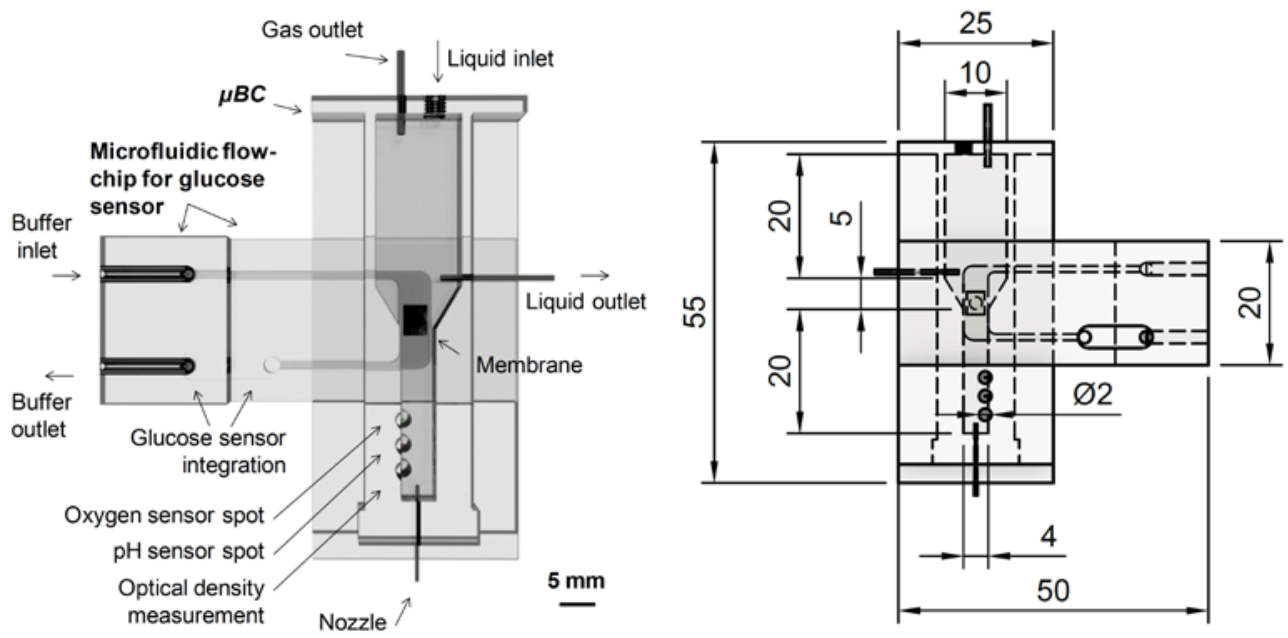

This article is protected by copyright. All rights reserved. 
Figure 2: Picture of the $\mu B C$ with the microfluidic flow chip and glucose biosensor; the inlets and outlets of the liquid and gas phases; and the integrated sensors for $p H$, dissolved oxygen and optical density with their associated glass fibers.
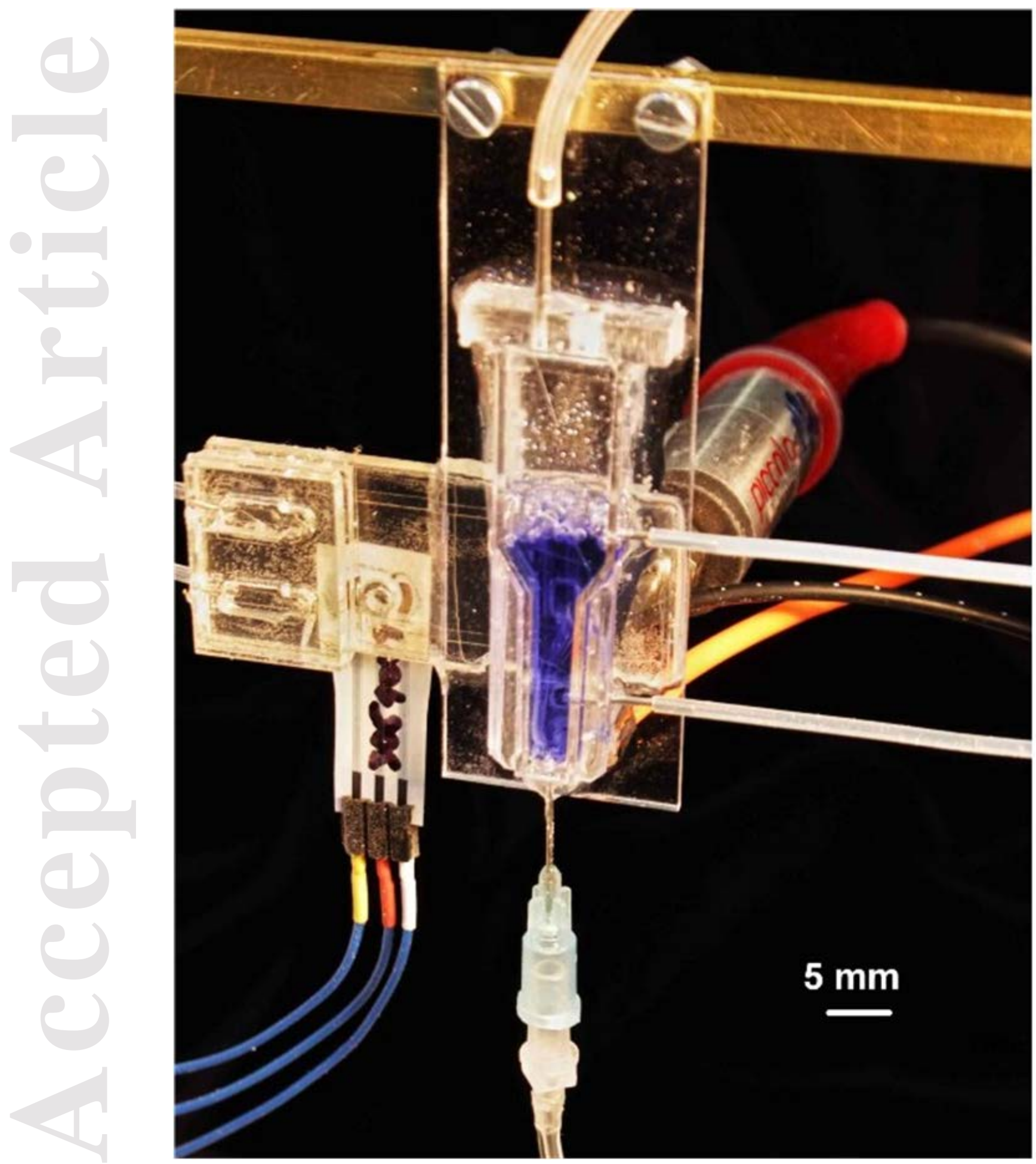

This article is protected by copyright. All rights reserved. 
Figure 3: (A) Sensing material applied (oxygen and $\mathrm{pH}$ sensor spots) onto the substrate with a microdispenser, (B) glucose sensor, and (C) two-dimensional microfluidic flow chip.

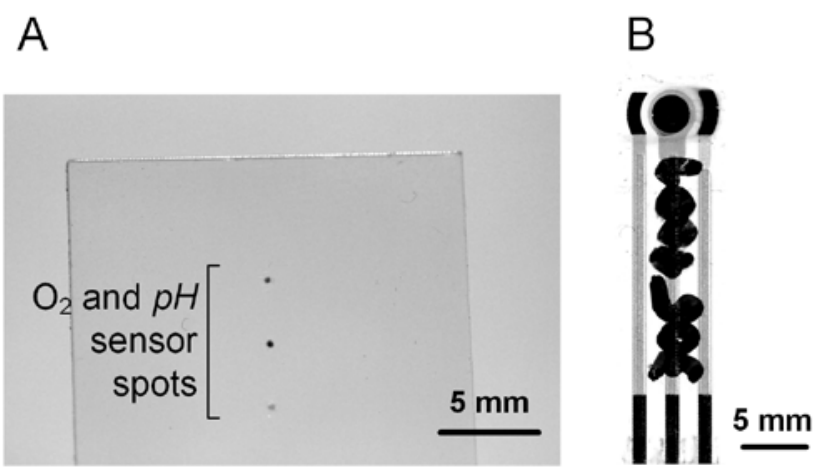

C

Figure 4: Example of the glucose sensor signal intensity with various diffusion times (in triplicates) applied to the microfluidic flow chip buffer at a flow time of $1.5 \mathrm{~min}$ and flow rate of $100 \mu \mathrm{L} / \mathrm{min}$ when the $\mu B C$ was filled with media with a glucose concentration of $5 \mathrm{~g} / \mathrm{L}$. Error bars indicate standard deviations.

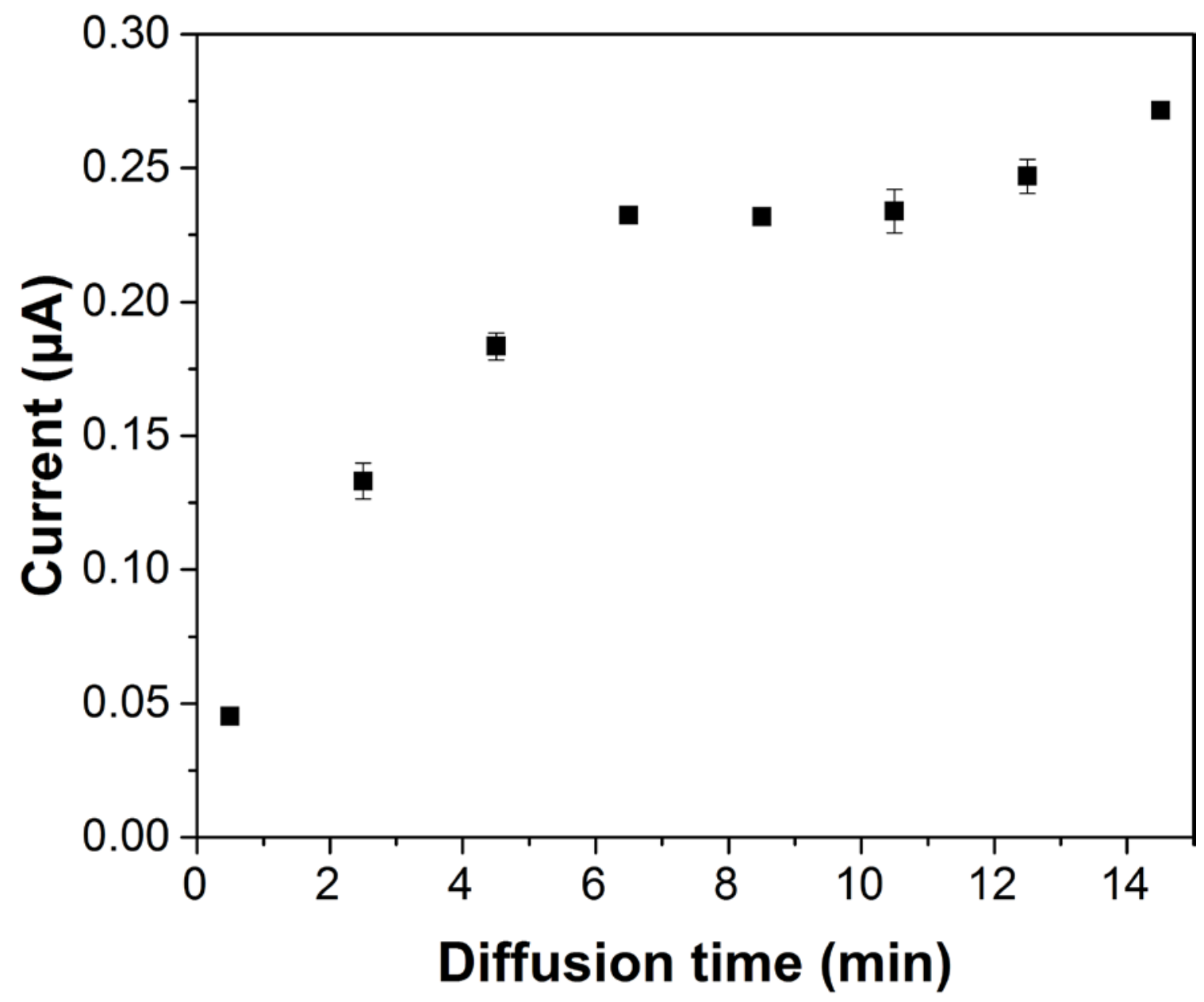

This article is protected by copyright. All rights reserved. 
Figure 5: Time-lapse image series of the $\mu B C$ with the air volume flow set at $6.2 \mu \mathrm{L} / \mathrm{s}$ and a gas superficial velocity of $3.0 \cdot 10^{-4} \mathrm{~m} / \mathrm{s}$ after the injection of a pulse of $5 \mu \mathrm{L}$ of the fluorescent tracer solution through a syringe pump. The images are shown with a frame rate of 3.3 fps.

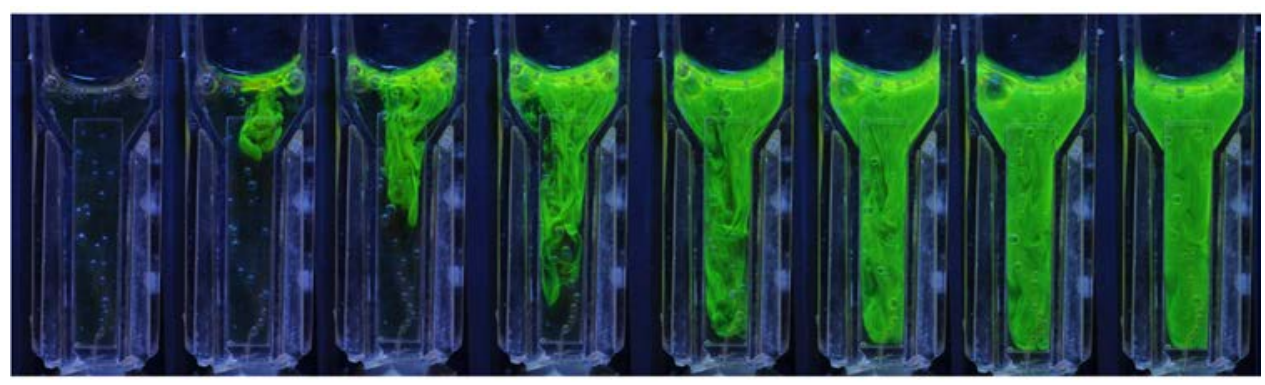

Figure 6: The percentage of dissolved oxygen $D O$ saturation changes in the $\mu B C$ during a gassing-out experiment in triplicate for the $k_{L} a$ determination.

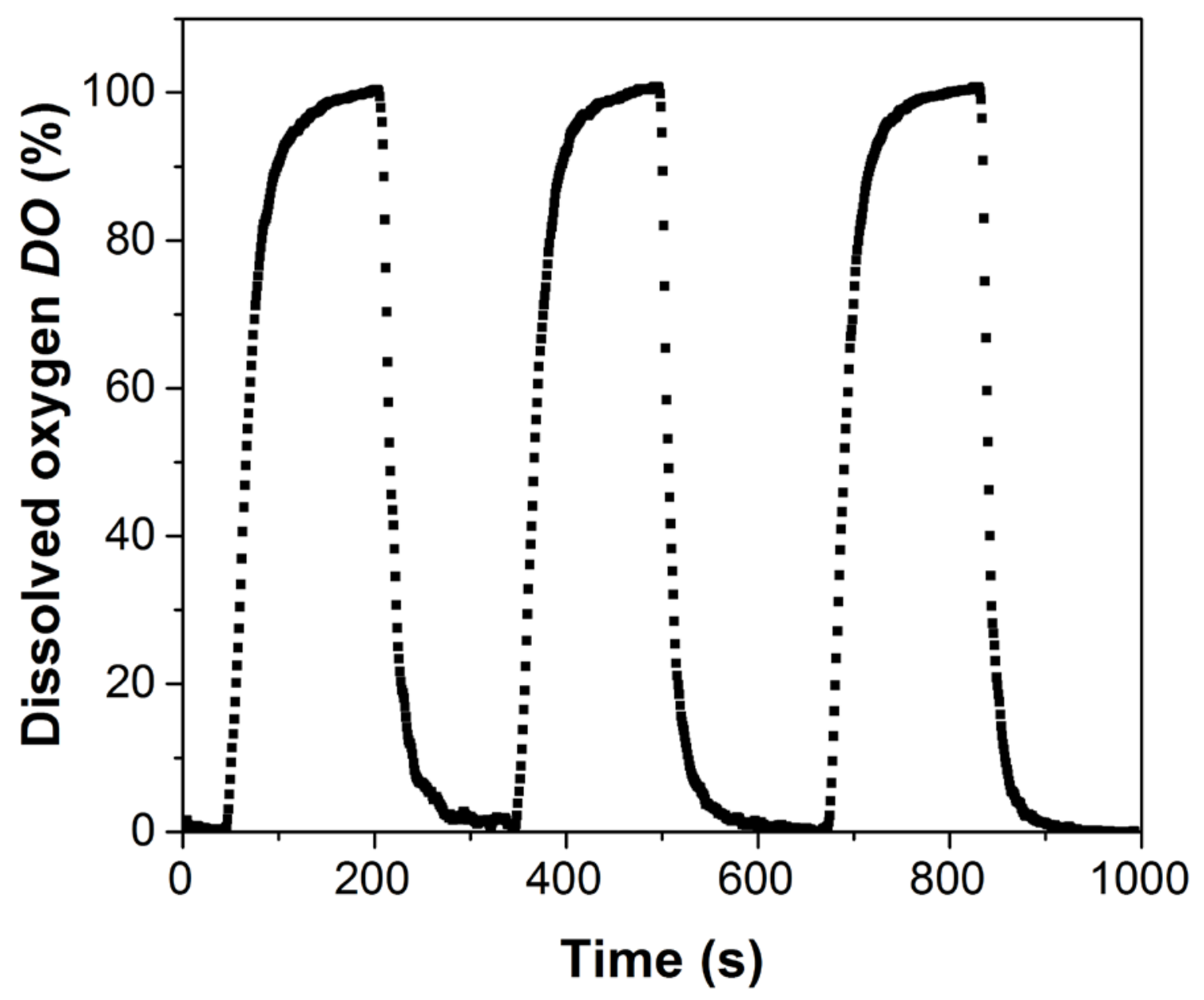

This article is protected by copyright. All rights reserved. 
Figure 7: Profile of the glucose concentration, cell dry weight concentration $C D W$, $p H$, dissolved oxygen $D O$ and oxygen uptake rate $O U R$ averaged from two independent batch cultivations of $S$. cerevisiae CCOS 538. The vertical dashed line indicates the end of the glucose-based growth and the start of the diauxic phase. The vertical pointed line indicates the end of the diauxic phase and the start of the ethanolbased growth phase. The cloud of every curve corresponds to the standard deviation of the averaged values.

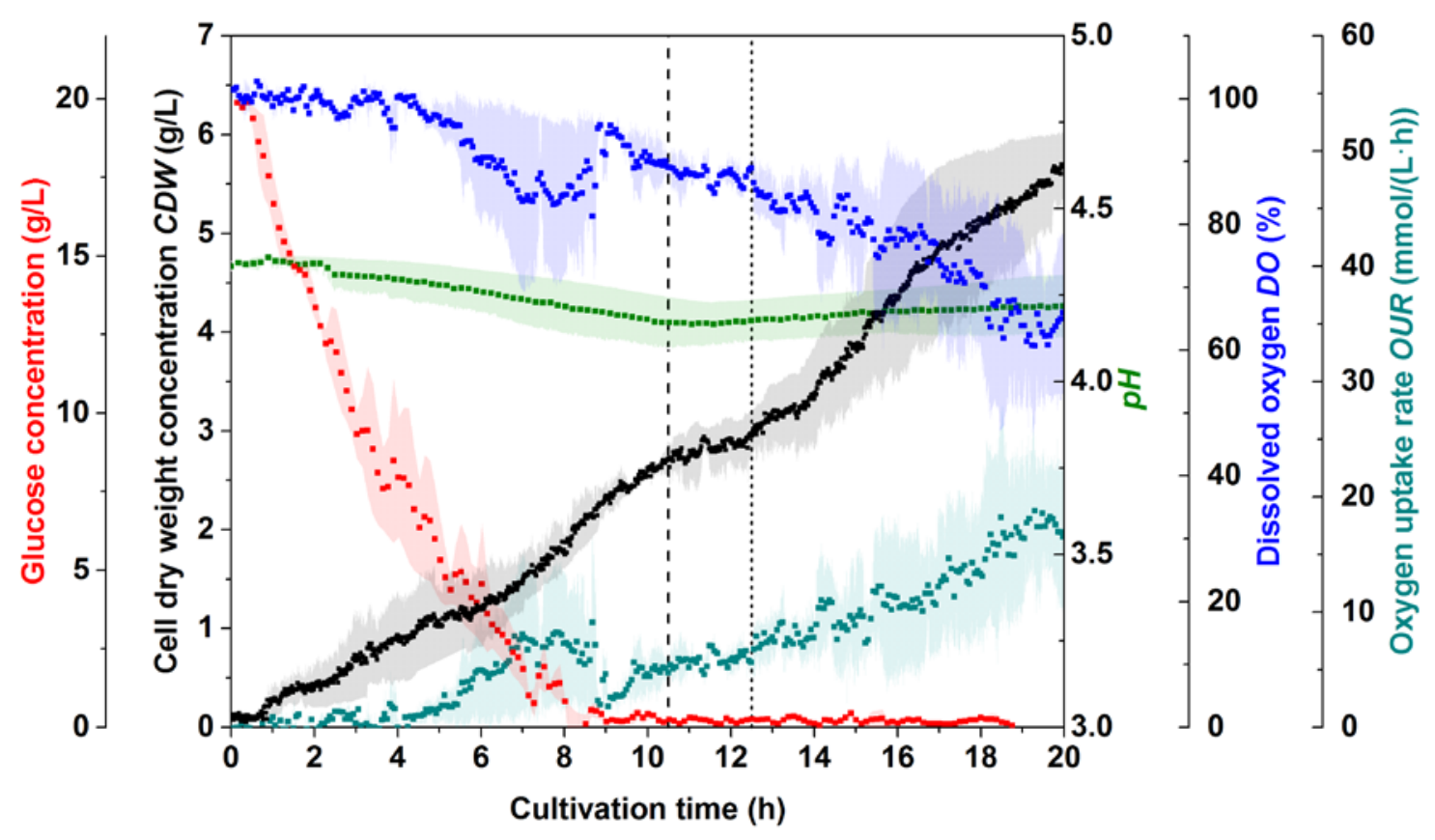

This article is protected by copyright. All rights reserved. 
Figure 8: Oxygen uptake rate $O U R$ as a function of the cell dry weight concentration $C D W$ averaged from two independent batch cultivations of $S$. cerevisiae. The area between vertical dashed and pointed lines indicates the diauxic phase (at a cell dry weight concentration $C D W$ of $\sim 3 \mathrm{~g} / \mathrm{L}$ ), a short period between the end of the glucosebased growth phase and the start of the ethanol-based growth phase. The slope represents the specific oxygen uptake rate $s O U R$, which was $2.0-2.5 \mathrm{mmol}$ $\mathrm{O}_{2} /\left(\mathrm{g}_{\mathrm{CDw}} \cdot \mathrm{h}\right)$ in the glucose-based growth phase and $2.5-4.5 \mathrm{mmol} \mathrm{O}_{2} /\left(\mathrm{g}_{\mathrm{CDW}} \cdot \mathrm{h}\right)$ in the ethanol-based growth phase.

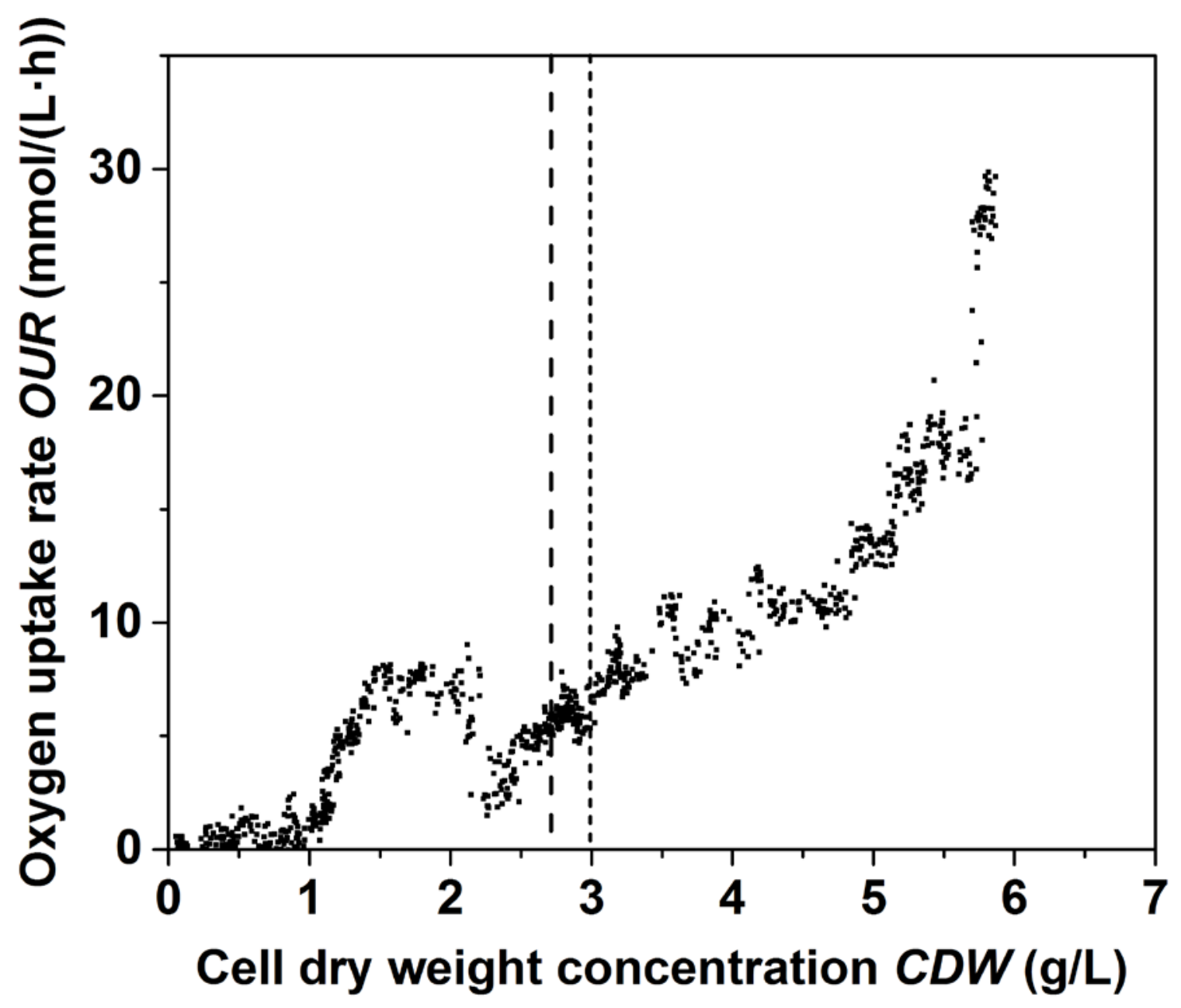

This article is protected by copyright. All rights reserved. 
Table 1: Composition of the sensor cocktails and primary surface modification layer used for microdispensing the chemical sensors. Adapted from Sun (Sun, 2017).

\begin{tabular}{|c|c|c|c|c|c|c|c|c|}
\hline \multirow{3}{*}{ Cocktail } & \multirow{3}{*}{ D4 (mg) } & \multirow{3}{*}{ THF (mg) } & \multirow{3}{*}{$\begin{array}{c}\text { Toluene } \\
\text { (mg) }\end{array}$} & \multirow{3}{*}{$\begin{array}{c}\text { Isopropanol } \\
\text { (mg) }\end{array}$} & \multirow{3}{*}{$\begin{array}{l}\text { Water } \\
\text { (mg) }\end{array}$} & \multirow{3}{*}{$\begin{array}{l}\text { Particles/ } \\
\text { Indicator } \\
\text { (mg) }\end{array}$} & \multirow{3}{*}{$\begin{array}{l}\text { Egyptian } \\
\text { Blue (mg) }\end{array}$} & \multirow{3}{*}{$\begin{array}{l}\text { Total } \\
\text { (mg) }\end{array}$} \\
\hline & & & & & & & & \\
\hline & & & & & & & & \\
\hline $\begin{array}{c}\text { Primary } \\
\text { layer - D4 }\end{array}$ & 250 & 2012.5 & 862.5 & N/A & N/A & N/A & N/A & 3125 \\
\hline $\begin{array}{c}\text { Oxygen } \\
\text { layer in } \\
\text { D4 }\end{array}$ & 250 & N/A & N/A & 2937.5 & 979.17 & 250 & N/A & 4416.67 \\
\hline $\begin{array}{l}p H \text { layer } \\
\text { in } D 4\end{array}$ & 500 & 5175 & N/A & N/A & 575 & 1.5 & 250 & 6501.5 \\
\hline
\end{tabular}

This article is protected by copyright. All rights reserved. 